\title{
THE CIRCULATORY EFFECTS OF ACUTE RESPIRATORY FAILURE: with special reference to ACUTE COR PULMONALE
}

\author{
G. DE J. LEE, M.A., M.D., M.R.C.P. \\ Consultant Physician, United Oxford Hospitals: Assistant Physician, Department of the Regius Professor \\ of Medicine, Radcliffe Infirmary, Oxford
}

Respiratory failure may be defined as the inability to maintain normal oxygen and carbon dioxide tensions in the arterial blood under normal atmospheric conditions. This condition will lead to serious functional disturbances of the cardiovascular system if hypoxia and hypercapnoea become severe. In addition, parenchymatous disease of the lungs, disorders affecting the mechanics of the thoracic compartment, and disorders affecting the lung blood vessels themselves will impair normal blood flow through the lungs. As a result of these changes the function of the heart and circulation will be disturbed, and will ultimately lead to congestive cardiac failure. Cor pulmonale may be defined as that group of circulatory disorders arising as a result of parenchymatous disease of the lungs themselves, and acute cor pulmonale may further be defined as heart failure secondary to acute parenchymatous lung disease associated with respiratory failure.

It is the purpose of the present paper to review the acute circulatory changes associated with respiratory failure, and also to discuss possible circulatory effects that may be produced by some of the resuscitative procedures often used in the treatment of patients with acute respiratory failure.

\section{Etiology}

\section{(1) Respiratory Failure Due to Extra-Pulmonary} Causes

Hypoxia and hypercapnœa from causes other than lung or chest-wall disease rarely present themselves as primary cardiovascular emergencies. However, severe degrees of hypoxia and carbon dioxide retention will lead to major cardiovascular disturbance. This in turn will ultimately end in the development of heart failure and contribute to the patient's death if unrelieved.

The extra-pulmonary causes of respiratory failure may be classified conveniently according to the system involved: (a) Brain:

Head injury.

Basilar artery thrombosis.

Pontine lesions.

Narcotic drugs.

(Carbon dioxide narcosis).

(b) Nerve transmission:

Poliomyelitis.

Polyneuritis.

High spinal cord lesions.

(c) Chest roall:

Myopathies.

Spondylitis. Thoracoplasty.

Kyphoscoliosis.

Extreme obesity.

Traumatic pneumothorax.

Disorders of the chest wall are commonly associated with chronic parenchymatous lung disease. This results from ineffective ventilation combined with failure to cough effectively, particularly at times when bronchial secretions are increased during acute respiratory infections. In such patients when the lung is already damaged acute infection, with sputum, may rapidly lead to airway obstruction and acute respiratory and cardiac failure.

\section{(2) Parenchymal Disorders of the Lungs}

- Chronic parenchymal disorders of the lungs comprise the largest source of disease associated with the development of cor pulmonale. Although these conditions commonly result in chronic heart disease, episodes of acute cor pulmonale may occur suddenly in such patients from time to time. These acute episodes are usually precipitated by the onset of an acute respiratory infection with productive sputum affecting an already seriously disorganized lung. Acute ventilatory failure ensues with the development of intense hypoxia and hypercapnœa which, in turn, lead to the development of acute right heart failure. The factors most concerned in precipitating heart failure in 
such conditions will be discussed in later sections.

The commoner lung conditions associated with cor pulmonale are listed below:

(a) Emphysema-associated conditions: Bronchitis, asthma.

(b) Lung fibrosis, with or without emphysema, due to:

Tuberculosis.

Pneumoconiosis.

Sarcoidosis.

Radiation fibrosis.

Carcinomatous lymphangitis.

\section{(3) Obstructive Pulmonary Vascular Disease}

Obstruction to the lumen of blood vessels of the lung either from changes occurring within the lumen or in the walls of the vessels will lead to right heart failure as a result of the development of obstructive pulmonary hypertension. Some of the causes of obstructive pulmonary hypertension are listed below:

Recurrent pulmonary embolism.

Pulmonary artery thrombosis.

Pulmonary venous thrombosis.

Polyarteritis nodosa.

Tumour embolism (chorion epithelioma).

Idiopathic pulmonary hypertension.

Bilharziasis.

Although obstructive pulmonary vascular disease is often classified as one subgroup of cor pulmonale, it is here considered to be outside the immediate sphere of interest for discussion in the present paper, and will therefore not feature in subsequent discussion.

\section{Functional Considerations}

Severe hypoxia and carbon dioxide retention produce well recognized effects upon both the pulmonary and systemic circulations by producing alteration in the vascular tone of both the arterial and venous systems. These changes are partly due to direct effects on the blood vessels themselves and also to reflex changes, and result in large changes in peripheral resistance which are accompanied by similar large changes in blood flow and regional perfusion.

\section{The Cerebral Circulation .}

Both hypoxia and hypercapnœa produce cerebral vasodilatation and increased cerebral blood flow (Kety and Schmidt, I948). In company with these changes there is a rise in cerebrospinal fluid pressure (Rich, Scheinberg and Belle, 1953) which may be accompanied by characteristic symptoms and clinical signs. Headache is commonly complained of, and ophthalmoscopic examination of the eyes reveals distended fundal vessels and papillodema in the severer casesڤ (Westlake, Simpson and Kaye, 1955). Thez presence of these ophthalmoscopic findings arę helpful clinical signs of dangerous hypercapnœa. $\leftarrow$

\section{The Systemic Peripheral Circulation}

Experimental hypercapnœa produces vasocon- $\frac{\overline{0}}{0}$ striction and a decrease in forearm blood flow $\overline{\frac{\bar{c}}{7}}$ when measured plethysmographically (McArdle Roddie, Sheppard and Whelan, 1957). Thiso effect can be abolished to a large extent in thes nerve-blocked limb, indicating that peripheralo vasoconstriction from carbon dioxide retention is $-\vec{\omega}$ largely reflex in origin. Systemic venous distensi- $\omega$ bility is also decreased during carbon dioxide inhalation in the normal subject (Watson, 1960) indicating that vasoconstriction also takes placew in the systemic venous system under such con-is ditions. It is reasonable to expect, if generalized venous constriction takes place in this way, thatw it would lead to a central redistribution of venouso blood away from the peripheral capacity vessels, with consequent distension of the central venouse system. This in turn might be expected to leadf to an increase in central venous pressure, which may be one of the factors responsible for the raised cardiac output so often found in patierfse with cor pulmonale. However, one is not justified? in applying such isolated observations in nornati man to patients with cor pulmonale witho further evidence; for clinical observation reveals that the superficial veins of the limbs are distended and the measured forearm blood flow in such patients is increased above the normal range $\stackrel{\varrho}{\rightarrow}$ These findings are probably partly due to theo peripheral circulatory effects of hypoxia. Experimental hypoxia usually produces a rise in peripheral blood flow (Anderson, Allen, Barcroft Edholm and Manning, 1946) partly due to an overall rise in blood flow due to an increase in: cardiac output (Doyle, Wilson and Warren, 1952 Assmussen and Nielsen, I955). In addition, the release of local metabolites from the hypoxic tissues may also be concerned in producing locab systemic arterial vasodilatation (Korner, 1959).

\section{The Kidney}

The effects of hypoxia and hypercapnœa upon renal blood flow and water and salt excretion by the kidney do not account for the renal behaviourw in cor pulmonale. In the normal subject hypoxia leads to an increase in renal blood flow and to aro increase in salt and water excretion (Berger, Galdston and Horwitz, 1949). However, in cor ${ }^{+}$ pulmonale the opposite occurs; renal blood flow: is reduced and there is intense water and salto retention by the kidney (Fishman, Maxwell $\frac{\rho}{\mathbb{Q}}$ 
Crowder and Morales, 1951). The normal renal response to increasing hypoxia (Berger, Galdston and Horwitz, 195I) still takes place in such circumstances, and relief of hypoxia by oxygen breathing may be shown to be associated with a further moderate decrease in renal blood flow in such cases. Thus the renal changes in cor pulmonale must be associated with mechanisms other than those produced by local hypoxia, but the mechanisms leading to renal vasoconstriction in cor pulmonale remain obscure.

In right-sided heart failure there is an increased excretion of aldosterone in the urine (Wolff, Koczorek and Buchborn, 1957) and it is probable that the increased production of this hormone is the major factor producing salt retention and oliguria in cor pulmonale. However, Campbell and Short (1960) suggest that respiratory acidosis itself may be an important contributory factor. These authors suggest that as a result of the high blood carbon dioxide tension in cor pulmonale there is an increase in the formation of carbonic acid in the renal tubular cells. Hydrogen ions are excreted into the tubules in exchange for sodium ions, which pass together with bicarbonate ions back into the blood. They suggest that this increased reabsorption of 'bicarbonate-bound base' could in turn lead to an expansion of the extracellular fluid volume. Experimental evidence to support their hypothesis is lacking.

\section{The Pulmonary Circulation}

Both hypoxia and hypercapnœa can be demonstrated to produce pulmonary arterial vasoconstriction and a rise in pulmonary vascular resistance (Doyle, Wilson and Warren, I952; Herz, 1956; Defares, Lundin, Aborelius, Stromblad and Svanberg, 1959; Manfredi and Sieker, 1960).

These adaptations, when occuring locally within the lung, help to maintain normal gas exchange, as their effect is to redistribute blood flow away from underventilated areas affected by local disease to more normal areas of the lung. In addition to the functional effects of abnormal gas tensions upon the lung blood vessels, the pulmonary vascular bed in disease is also reduced by obliterative and destructive changes. The normal pulmonary vascular bed presents a very low resistance to blood flow and has a large and distensible capacity, so that at least twice the normal resting blood flow can be accommodated with very little change in pulmonary arterial resistance. Indeed, removal of one lung, provided the remaining lung is normal, is accompanied by very little change in pulmonary arterial pressure at rest, in spite of the fact that only one lung is now accommodating the total output from the right ventricle.
It follows that the volume of the pulmonary vascular bed must be grossly reduced before its reduction will become an important factor in causing pulmonary hypertension. However, serious reduction of the pulmonary vascular bed becomes an increasingly important factor in the late stages of emphysema. This is probably the main factor responsible for the persistently raised pulmonary arterial pressure at rest, and its further rise with exercise, seen in severer cases of emphysema (Hickam and Cargill, 1948).

\section{The Heart}

Acute hypoxia causes an increase in pulse rate, and a rise in cardiac output in the normal heart (Assmussen and Nielsen, 1955; Doyle, Wilson and Warren, 1952) partly due to the increase in heart rate and partly due to an increase in stroke volume. The mechanisms involved in producing the rise in cardiac output are complicated and they are well reviewed by Korner (1959). Part of the hypoxic cardiac output response may be due to an increase in circulating adrenaline, and part to both the direct and reflex effects upon the systemic and pulmonary circulations of hypoxia already discussed. The increased heart rate and stroke volume are also due to a combination of direct humoral and reflex stimulation of the heart itself.

In cor pulmonale the work of the heart is increased both as a result of the increased pulmonary vascular resistance, and also as a result of the increased cardiac output that takes place. This increase in work associated with severe myocardial hypoxia accelerates the development of heart failure. McMichael and Sharpey-Schafer (1944) first showed that the cardiac output was often raised in patients with chronic cor pulmonale. However, they also recognized a group of patients with cor pulmonale in whom the cardiac output and blood pressure were below normal (Howarth, McMichael and SharpeySchafter, 1948). Clinical experience of patients with severe cor pulmonale indicates that this low output state usually follows in patients who have previously had all the signs of a well maintained or elevated cardiac output. The fall in cardiac output is usually a terminal event and indicates biventricular heart failure, caused by gross hypoxæmia.

The end-diastolic pressure within the failing right ventricle is elevated (Ferrer, Harvey, Cathcart, Webster, Richards and Cournand, 1950) as are the right atrial and central venous pressures. While the failing right ventricle is still able to maintain a normal or high cardiac output it usually responds normally to a reduction in filling 
pressure. Thus lowering the right atrial pressure by venesection will lead to a fall in cardiac output in this group of cases (Howarth, McMichael and Sharpey-Schafer, 1948). This may have serious consequences if practised therapeutically in those cases of cor pulmonale with high cardiac output. Digitalis treatment is often ineffective in this group as opposed to those showing evidence of superimposed left ventricular failure and a low cardiac output. Here both venesection and digitalis therapy often produce clinical improvement and a rise in cardiac output.

There is no simple explanation for the divergent behaviour of the failing right and left ventricles. However, animal studies by Sarnoff and Berglund (1954) suggest a possible explanation. These workers have restudied Starling's law of the heart in the dog, using an intact circulation in place of the heart-lung preparation. Amongst other information, they obtained ventricular function curves from the right and left ventricles simultaneously when each ventricle was submitted to stepwise increases in atrial filling pressure. The work response curves of the two ventricles under many conditions were obtained, including the effects of myocardial failure produced by experimental occlusion of the left main coronary artery. Sarnoff and Bergland re-emphasized the fact that only part of the external work of the heart is expended in maintaining cardiac output. The other main cause for work is pressure-work spent in overcoming the pulmonary and systemic vascular resistances. Normally, because of the low pulmonary vascular resistance, right ventricular work is considerably less than that of the left ventricle, but it may rise to systemic levels if pulmonary hypertension is present. Sarnoff and Berglund also showed that the work-response of the left ventricle to increasing levels of filling pressure was curvilinear, and confirmed that the stroke-volume response of the failing left ventricle was also curvilinear. However, the workresponse curve of the failing right ventricle always tended to remain linear. If these findings in the experimental animal are applied liberally to man, then the normal or raised cardiac output of cor pulmonale and the low cardiac output of left ventricular failure may be explained as the results of the linear and curvilinear responses to filling pressure of the failing right and left ventricles respectively.

\section{Acute Cor Pulmonale Incidence and Prognosis}

Acute cor pulmonale will develop in any patient with severe chronic lung disease in whom respiratory failure develops. By far the commonest

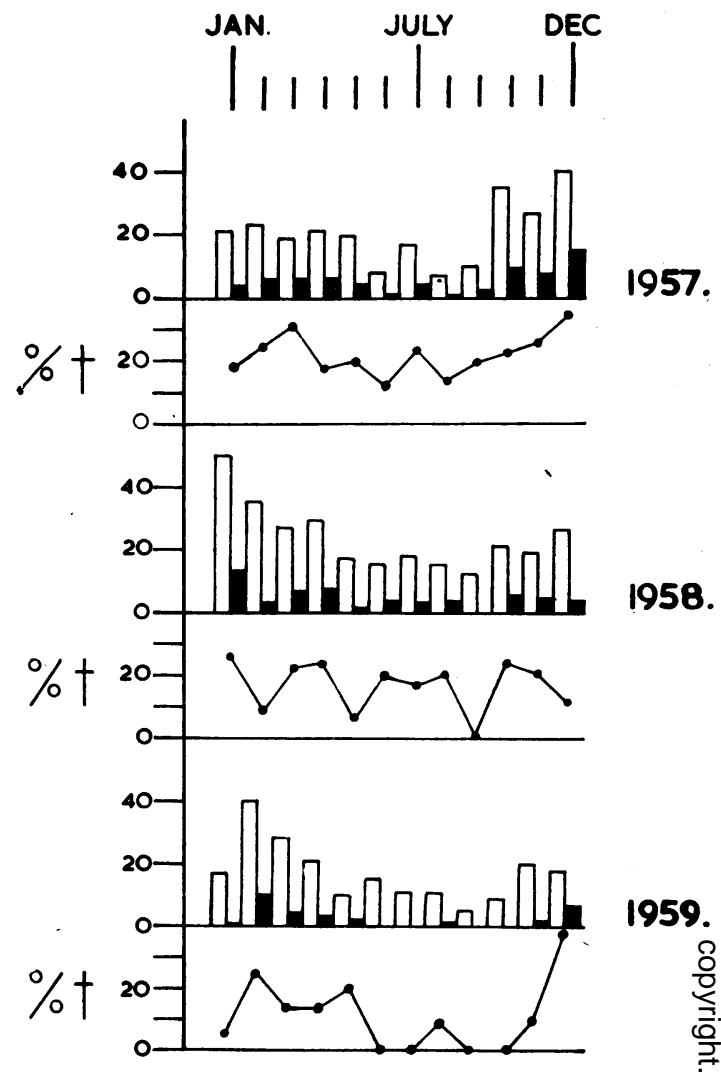

FIG. 1.-Monthly admissions, aged 40-70, with emphysema and related conditions, to the United Oxford Hospitals, 1957-59, and percentage of deaths.

precipitating factor in such patients is an acute respiratory infection such as acute bronchitis or bronchopneumonia. The early diagnosis and $\frac{\bar{\partial}}{\partial}$ effective use of oxygen is life-saving in such 3 . patients, for if hypoxia is not quickly relieved death from heart failure soon follows. This opinion is based upon the analysis of cases ad- $\delta$ mitted to the United Oxford Hospitals during the three years 1957-59.

Fig. I shows the number of patients with $D$ emphysema and related conditions between the ages of 40 and 70 years admitted to the United Oxford Hospitals for each month during the period 1957-59. The black columns indicate the ${ }_{0}$ number of patients admitted who subsequently ${ }_{\omega}^{N}$ died; and the percentage of patients dying in each month is shown below the columns for that 0 month. Notice that there was a steep rise in admissions with emphysema and related condi- $\stackrel{0}{+}$ tions during the winter of $1957-58$. There was also a steep rise in the number of deaths at this time. This finding coincided with the $1957-5^{8}$ 
influenza epidemic and a high incidence of acute staphylococcal pneumonia at that time.

Chases were selected for this survey in the following manner: The total number of patients admitted to the United Oxford Hospitals during the period of study who were coded at the time of death or discharge as having had some form of respiratory disease or cor pulmonale, or both, was first ascertained; 1,964 cases in this general group were admitted in three years. The notes of each case were then examined and the coded diagnosis verified against the recorded history, physical examination and appropriate investigations. It became plain that wide interpretation of the clinical findings led to the coded diagnosis and that often relevant clinical findings and investigations were scanty or missing. For this reason all patients under the age of 40 years were excluded from the survey, as it was thought that they were unlikely to have had time to develop emphysema or other forms of chronic non-specific lung disease. Chronic non-specific lung disease was defined as being present if one or more of the following symptoms were recorded: Chronic cough with sputum, and paroxysmal or persistent excessive breathlessness not solely attributable to $(a)$ cardiovascular or renal disease, $(b)$ chest wall disease, (c) psychoneurosis, or $(d)$ collagen diseases (Report of a Ciba Foundation Symposium, 1959). Patients over the age of 70 years were also excluded from the analysis because it was found that, although chronic non-specific lung disease was common, acute toxæmia from respiratory infection or left ventricular heart failure could not be excluded as the primary cause of death in a large proportion of patients dying in this age group.

During the period 1957-60 739 cases between the ages of 40 to 70 years thus remained who had evidence of emphysema or other chronic nonspecific lung disease, with superimposed signs to suggest that their admissions were due to an acute respiratory infection, respiratory failure, or cor pulmonale. Cor pulmonale was presumed to be present if any one or more of the following findings were recorded:

A persistently raised jugular venous pressure.

Clinical evidence of right heart hypertrophy.

Gallop rhythm.

Liver enlargement.

Ascites or œdema.

ECG appearances of:

Right axis deviation.

Dominant $R$ in $V_{1}$ and deep $S$ in $V_{5}$.

Inverted $T$ in $V_{1-3}$.

Right bundle branch block.

$P$ pulmonale.

The arbitrary selection of cases here reported
EMPHYSEMA and RELATED CONDITIONS

DEATHS

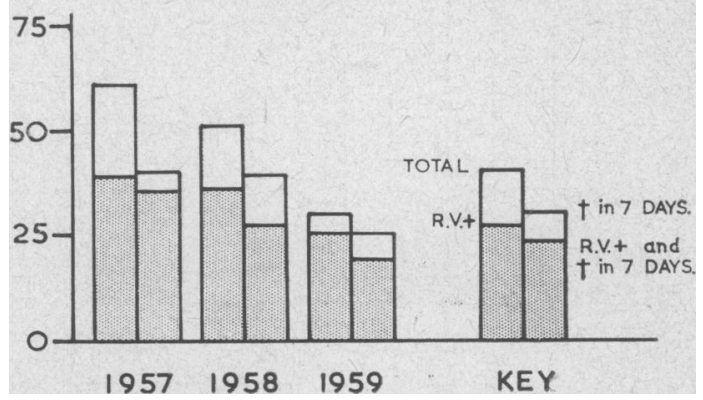

FIG. 2.-Annual admissions and deaths from emphysema and related conditions.

Left-hand column: Total number; hatched area indicates those with cor pulmonale (R.V. + ).

Right-hand column: Deaths.

TABLE I

Admissions AND DeATHS FROM EMPHYSEMA AND Related Conditions

\begin{tabular}{|c|c|c|c|c|c|}
\hline \multirow[t]{2}{*}{ Year } & $\begin{array}{c}\text { (I) } \\
\text { Admis } \\
\text { sions }\end{array}$ & \multicolumn{2}{|c|}{$\begin{array}{c}\text { (2) } \\
\text { Admissions } \\
\text { with Right } \\
\text { Ventricular } \\
\text { Disease }\end{array}$} & \multicolumn{2}{|c|}{$\begin{array}{c}\text { (3) } \\
\text { Deaths }\end{array}$} \\
\hline & No. & No. & $\%$ of $(x)$ & No. & $\%$ of $(x)$ \\
\hline $\begin{array}{ll}1957 & \ldots \\
1958 & \ldots\end{array}$ & $\begin{array}{l}251 \\
283\end{array}$ & $\begin{array}{l}93 \\
99\end{array}$ & $\begin{array}{l}37 \\
35\end{array}$ & $6 \mathrm{I}$ & $\begin{array}{l}24 \\
18\end{array}$ \\
\hline 1959 & 205 & 61 & 30 & 30 & 15 \\
\hline Total & 739 & 253 & - & 142 & - \\
\hline $\begin{array}{l}\text { Average } \\
\text { per year }\end{array}$ & 246 & 84 & 34 & 47 & 19 \\
\hline
\end{tabular}

was all that was possible from this retrospective survey of the hospital notes.

Table $I$ and Fig. 2 show the number of admissions each year with emphysema and related conditions aged 40 to 70 years. The number of admissions showing some evidence of cor pulmonale amounted to $37 \%$ of the total admissions in $1957,35 \%$ in 1958 and $30 \%$ in 1959 (average $34 \%$ ). Table I and Fig. 2 also show the number of deaths with emphysema and related conditions occurring each year, being $24 \%$ of those admitted in $1957,18 \%$ of those admitted in 1958 , and $15 \%$ in 1959 (average $19 \%$ ).

The number and percentage of total deaths for each year that took place within seven days of admission was next obtained. Patients dying within seven days of admission could have done so from one of three main causes, or their combination, namely, toxæmia following infection, acute respiratory failure, or acute cor pulmonale. As discussed in the previous section under func- 
EMPHYSEMA and RELATED CONDITIONS.

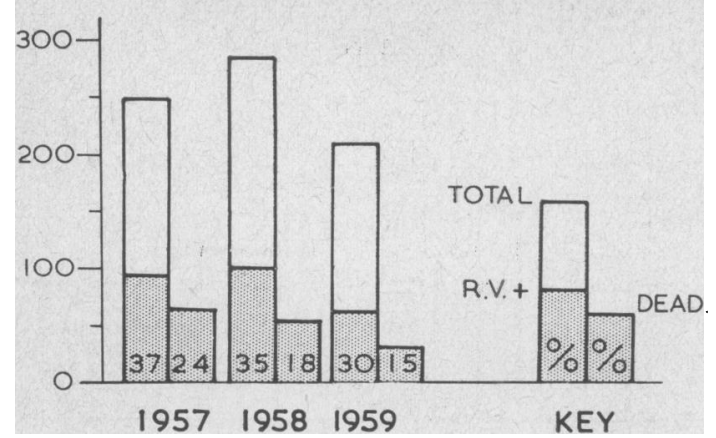

Fig. 3.-Analysis of deaths from emphysema and related conditions.

Left-hand column: Total number of deaths; hatched area indicates those with cor pulmonale (R.V.+).

Right-hand column: Number dying within seven days of admission; hatched area indicates proportion with cor pulmonale (R.V.+).

TABLE 2

Deaths from Emphysema and Related Conditions

\begin{tabular}{|c|c|c|c|c|c|c|c|c|}
\hline \multirow[t]{2}{*}{ Year } & Deaths & \multicolumn{2}{|c|}{$\begin{array}{c}\text { (2) } \\
\text { Deaths } \\
\text { With } \\
\text { Right } \\
\text { Ventri- } \\
\text { cular } \\
\text { Disease } \\
\text { (R.V.+) }\end{array}$} & \multicolumn{2}{|c|}{$\begin{array}{l}\text { (3) } \\
\text { Deaths } \\
\text { Within } \\
7 \text { Days }\end{array}$} & \multicolumn{3}{|c|}{ (4) } \\
\hline & No. & No. & $\begin{array}{c}\% \text { of } \\
\text { (I) }\end{array}$ & No & $\begin{array}{c}\% \text { of } \\
\text { (I) }\end{array}$ & No. & $\begin{array}{c}\% \text { of } \\
\text { (I) }\end{array}$ & $\begin{array}{c}\% \text { of } \\
\text { (2) }\end{array}$ \\
\hline $\begin{array}{ll}1957 & \ldots \\
1958 & \ldots \\
1959 & \ldots\end{array}$ & $\begin{array}{l}61 \\
5 I \\
30\end{array}$ & $\begin{array}{l}38 \\
36 \\
25\end{array}$ & $\begin{array}{l}62 \\
70 \\
83\end{array}$ & $\begin{array}{l}39 \\
39 \\
25\end{array}$ & $\begin{array}{l}64 \\
76 \\
83\end{array}$ & $\begin{array}{l}36 \\
27 \\
19\end{array}$ & $\begin{array}{l}59 \\
53 \\
63\end{array}$ & $\begin{array}{l}92 \\
69 \\
76\end{array}$ \\
\hline Total .. & 142 & 99 & - & 103 & - & 82 & - & - \\
\hline $\begin{array}{l}\text { Average } \\
\text { per year }\end{array}$ & & 3 & 70 & & 74 & 27 & 58 & 79 \\
\hline
\end{tabular}

tional considerations, acute respiratory failure may be expected to lead to the development of acute cor pulmonale. Therefore the cases dying in the first week were also divided into two groups: those showing no clinical, electrocardiographic or post-mortem evidence of right ventricular failure or hypertrophy, and those who showed these changes.

Fig. 3 and Table 2 show the results of this analysis. The average number of deaths per year was 47 , and $74 \%$ (34 cases) of these deaths occurred within the first seven days of admission. Right ventricular failure or right ventricular enlargement was present in an average of $79 \%$ of those patients who died within seven days of admission.
Finally from Tables $I$ and 2 it can be seen that an average of 84 patients per year who were admitted with emphysema and related conditions had evidence of right ventricular disease, of whom $33(39 \%)$ died.

One may summarize the findings from this survey as follows:

(a) $20 \%$ of all patients admitted to hospital with emphysema or related conditions died.

(b) $34 \%$ of these admissions had some evidence of right heart disease.

(c) $39 \%$ of the patients who died showed evidence of right heart disease.

(d) $74 \%$ of the deaths occurred within seven days of hospital admission. Of these, threequarters had evidence of right heart disease.

I believe that this survey strongly suggests that rapidly ensuing deaths in patients with acute or chronic lung disease is due to acute cor pulmonale superimposed upon acute respiratory failure, whether infection is present or not. This implies that therapy in this group of patients must be applied as early as possible if the patient is to survive.

Diagnosis of Acute Cor Pulmonale with Respiratory Failure

Patients developing acute cor pulmonale wit' $\overrightarrow{\mathscr{C}}$ respiratory failure will usually have a long previous o history of chronic cough with acute episodes af breathlessness associated with infection and the production of increased amounts of often purulent sputum. It is these acute episodes that so often precipitate acute respiratory failure with cor pulmonale. The patient is usually deeply cyanosed, confused or semi-conscious. The respiratory rate is increased and the tidal volume small. The patient often breathes in a fish-like way, expirations being prolonged and the lips pursed in a characteristic puffing manner. The pulse is usually bounding and regular in rhythm. The arms and legs, ears and nose are warm. The blood pressure may be elevated with a wide pulse pressure. The jugular venous pressure is usually elevated but its true level may be difficult to distinguish clearly as a result of superimposed pressure swings resulting from the great variations in intrathoracic pressure due to the patient's respiratory efforts. The apex beat may be unlocalizable if the patient is emphysematous, but a heaving right ventricular impulse may lift the sternum and the hypertrophied heart may be felt protruding beneath the xiphisternum on palpation of the abdomen.

On auscultation, a gallop rhythm is commonly heard and the pulmonary second sound may be $\stackrel{\infty}{\sim}$ widely split and accentuated, suggesting the presence of pulmonary hypertension. The liver may be enlarged and tender. Ascites and depend- 


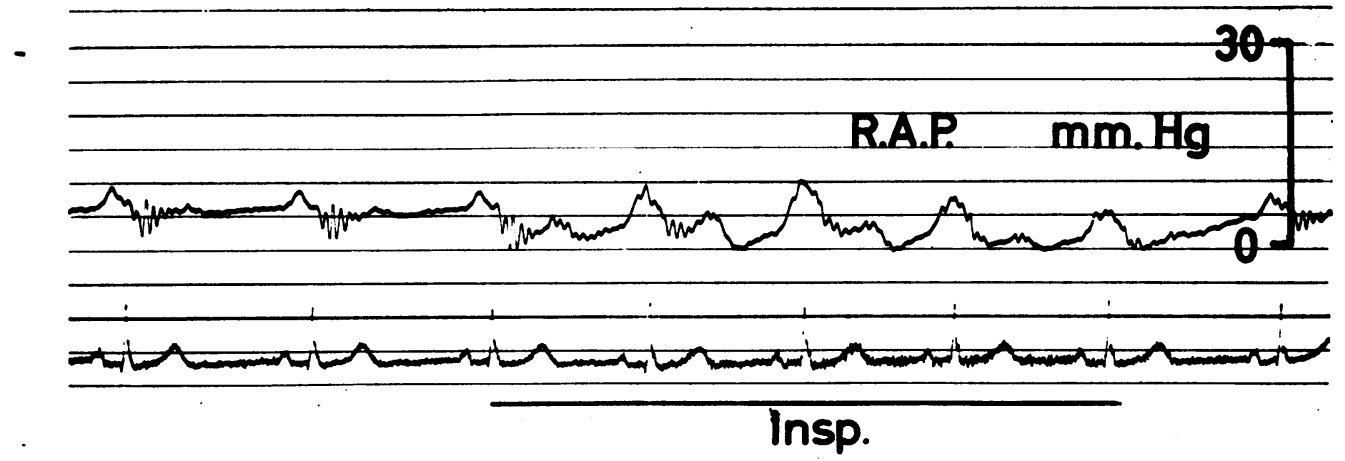

FIG. 4.-Packed pulmonary embolism. Right auricular pressure (RAP) showing prominent auricular contraction wave, which becomes more accentuated during inspiration.

ent œdema are common features. The urine is scanty and contains albumin.

Examination of the lungs will confirm the presence of underlying chronic lung disease and often the presence of a superimposed acute lung infection. In the central nervous system ophthalmoscopy reveals distended fundal veins and even papillœedema. The limbs often show involuntary jerky movements, active movements may be inco-ordinated, and the tendon reflexes may be decreased with absent plantar responses.

The electrocardiograph is often of low voltage if emphysema is present. Tall spiked pulmonary $P$ waves are commonly seen. The heart is usually vertical with intense clockwise rotation and right axis deviation. In the chest leads a dominant $R$ wave in $V_{1}$ with $T$ inversion in $V_{1}-V_{3}$ with a conspicuous $S$ wave in $V_{5}$ indicates right ventricular hypertrophy with strain. Various degrees of right bundle-branch block may be seen.

In spite of the deep central cyanosis and the apparent plethora of the patient the hæmoglobin is elevated in a minority of patients only. Analysis of the arterial blood gases will reveal gross oxygen desaturation ( $40 \%$ or less) with dangerously elevated carbon dioxide tensions $\left(\mathrm{PCO}_{2} 70 \mathrm{~mm} . \mathrm{Hg}\right.$ or more). Estimations of venous plasma bicarbonate may show high levels of $32 \mathrm{mEq}$./1. or more.

If treatment is not effective, increasing respiratory depression and worsening cardiac failure will ensue. Manifestations of these events are deepening coma, deepening cyanosis, a rising pulse rate, falling blood pressure, and increasing peripheral vasoconstriction recognizable by the development of cold extremities. These findings indicate a falling cardiac output and are grave prognostic features.

\section{Complications}

Particularly in those patients who have been bed-bound for long periods, pulmonary embolism. from deep leg vein thrombosis may complicate the already serious situation. Sudden collapse with pallor, sweating, fast pulse and sudden fall in blood pressure would suggest such a diagnosis, particularly if leg odema is unequal or calf vein tenderness or redness is present. The jugular venous pressure usually rises rapidly in such cases and may show a paradoxical rise on inspiration with the appearance of prominent auricular waves also becoming more prominent on inspiration (Fig. 4). These striking changes in the jugular venous pressure indicate acute right ventricular overload as a result of acute obstructive pulmonary hypertension from the pulmonary embolism.

\section{Treatment of Acute Cor Pulmonale with Respiratory Failure}

Unless effective oxygenation of the arterial blood is rapidly produced the patient will die from a combination of cerebral depression and heart failure in the manner already outlined in previous sections.

The administration of oxygen to patients with bronchitis and emphysema and respiratory failure with gross hypoxæmia and carbon dioxide retention presents considerable practical difficulties, for the abnormal gas contents of the arterial blood combine to depress the cerebral centres. Oxygen therapy will tend to remove the hypoxic stimulus to the aortic chemoreceptors so that further respiratory depression and apnœa may be precipitated as the hypoxic response is removed. Intermittent oxygen therapy has serious disadvantages (Campbell, I960) and more effective measures for oxygen administration consist of providing oxygen-enriched gas mixtures $(25-30 \%$ oxygen) combined with the use of intravenous or frequently repeated intramuscular injections of large doses of Nikethamide $(4-8 \mathrm{ml}$. i.m. fourhourly) as a means of stimulating respiration (Campbell, 1960; Campbell and Westlake, 1958). 
However, this method of stimulating respiration in the comatose patient is often ineffective, while in the less narcotized patient the large doses of analeptics excite the most unpleasant side-effects of skin irritation, etc. In addition to oxygen therapy it is essential to combat any acute respiratory infection by broad spectrum antibiotics until sputum culture for organism sensitivity indicates a more effective antibiotic. The next most important measure is to improve ventilation by assisting sputum elimination with physiotherapy and postural drainage. However, this is often distressingly ineffective or the patient too ill to withstand the energetic manhandling required. For this reason early and elective tracheostomy is the treatment of choice because of the following great advantages:

(I) The anatomical dead space is decreased with consequent increase in alveolar ventilation.

(2) The patient's secretions can be effectively and frequently aspirated with a sucker and catheter passed through the tracheostomy tube into the main bronchi.

(3) Liquefaction of muco-purulent sputum may be aided by the use of an efficient humidifier delivering a high flow of water-saturated, oxygen-enriched, air to the mouth of the tracheostomy.

Fig. 5 is a schematic diagram which shows the carbon dioxide concentration of gas leaving the mouth during expiration from a patient with emphysema (solid line). During the first $150 \mathrm{ml}$. of expiration the expirate contains practically no carbon dioxide as the air in the dead space of the trachea and mouth is being washed out at this time. Then the gas from the lung itself is eliminated and the carbon dioxide content of the expired air leaving the mouth rises steeply. Tracheostomy will eliminate approximately $100 \mathrm{ml}$. of mouth and tracheal dead space. In patients with high alveolar carbon dioxide tensions this will allow an increase of 4-8 ml. of carbon dioxide per breath to be eliminated from the patient (interrupted line, Fig. 5). If this benefit is to be obtained from tracheostomy it is obviously essential to use a cuffed tracheostomy tube, otherwise the patient's breath will flow past the tube and elimination of the upper airway dead space will not have been accomplished. Secondly, it is essential to use a humidifier to prevent drying of the sputum and it is also essential that the humidifier be equipped with an efficient blower, otherwise the patient's upper airway dead space will be exchanged and may actually be increased by the volume of the humidifier tubing, and again the usefulness of the tracheostomy will have been lost If ventilatory failure and further respiratory depression still occur, assisted ventilation by inter-

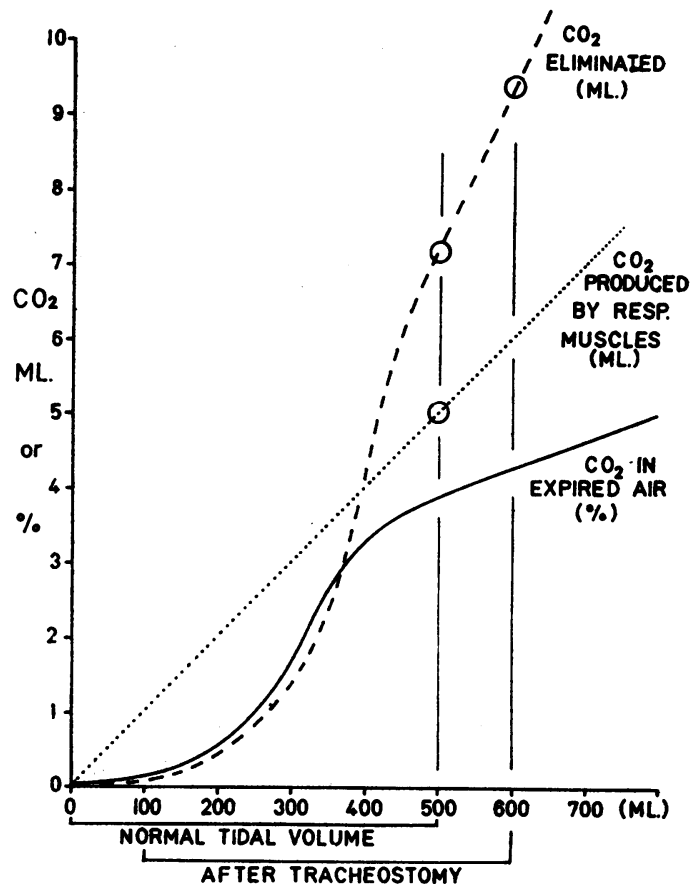

Fig. 5.-Diagram showing the relationship between anatomical dead space, carbon dioxide content of expired air, and volume of carbon dioxide elimino ated during expiration, before and after trach ostomy.

mittent positive pressure ventilation may be applied mechanically via the cuffed tracheostomy tube.

Provision of effective ventilation with consequent increase in arterial oxygen saturation and carbon dioxide elimination is the first priority in the treatment of the heart. For the elimination of myocardial anoxia will assist its function and the return towards normal gas tensions in the lungs will reduce pulmonary vascular constriction and reduce the load on the right ventricle.

Full doses of digitalis or ouabaine (0.25 mg. i.v. six-hourly) may be given, but their effects are often disappointing. If the cardiac output is well maintained, as indicated by warm pulsating arms and legs, venesection has no place and may be dangerous (Howarth, McMichael and SharpeySchafer, 1948).

The use of morphine or sedatives may precipitate complete respiratory depression even in homœopathic doses and the control of the confused and restless patient with respiratory failure and cor pulmonale is a difficult therapeutic problem, sometimes more easily overcome by planned sedation and the use of a mechanical respirator. However, if tracheostomy and bronchial aspiration are performed early, a large proportion of patients 

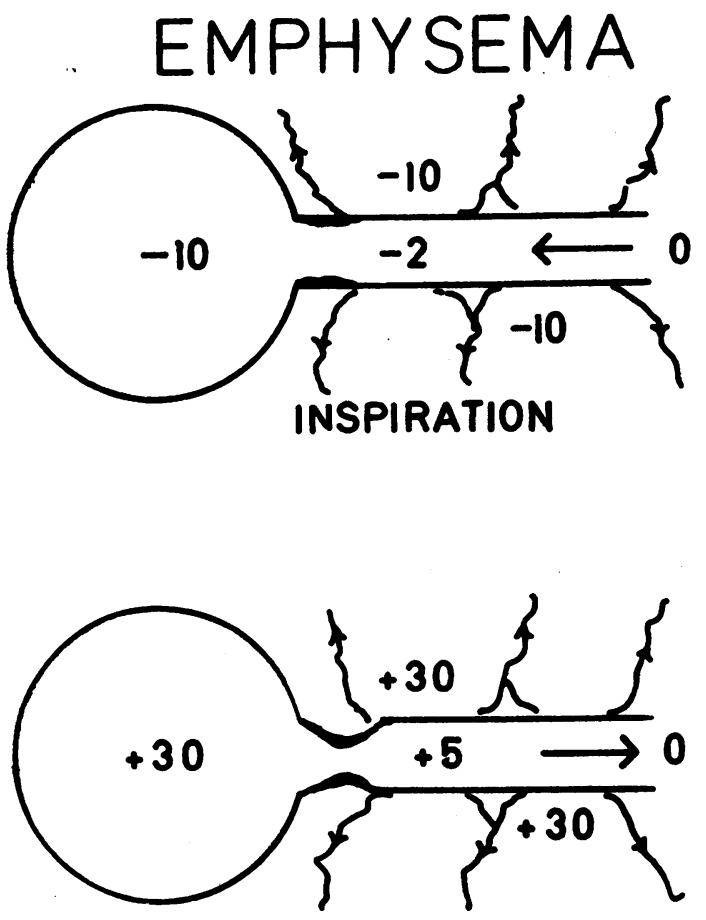

EXPIRATION

FIG. 6.-Diagram depicting the mechanism producing air trapping in emphysema.

with acute respiratory failure and cor pulmonale will improve without the need of intermittent positive pressure respiration.

Intermittent positive pressure respiration in patients with respiratory failure, although sometimes life-saving, has particular practical hazards when applied to emphysematous patients in respiratory failure. These will now be considered.

\section{Some Circulatory Effects of Intermittent Positive Pressure Respiration in Emphysema and Cor Pulmonale}

Fig. 6 is a diagram of the type of changes occurring within the lungs of an emphysematous patient. During inspiration the intra-alveolar pressure is shown as $-10 \mathrm{~mm} . \mathrm{Hg}$. As a result of this negative pressure air is drawn into the lungs, and there is a gradient of pressure between the alveoli (-10 mm.Hg), respiratory bronchioles (-2 $\mathrm{mm} . \mathrm{Hg}$ ) and main bronchi (o $\mathrm{mm} . \mathrm{Hg}$ ). However, during expiration the reverse occurs. The alveolar pressure rises $(+30 \mathrm{~mm} . \mathrm{Hg})$ and because of the damage to the alveolar systems and respiratory bronchioles the normal bronchial supporting structure is destroyed and the high intraalveolar pressure tends to overcome the low bronchiolar pressure. As a result, invagination of the walls of the respiratory bronchioles takes place and the normal emptying of alveolar systems is prevented with consequent air trapping. This is recognized clinically by a prolonged expiratory period and a reduction in the one-second forced expiratory volume test. If intermittent positive pressure ventilation is applied to patients with severe air trapping it may produce serious changes in intra-alveolar pressure. Consider the expiratory phase in Fig. 6. Air trapping occurs with a net intrathoracic pressure of $25 \mathrm{~mm} . \mathrm{Hg}(30 \mathrm{~mm}$. alveoli-5 $\mathrm{mm}$. bronchioles).

If the main air passages are partially obstructed by secretions the positive phase of ventilation by the mechanical pump applied to the patient's tracheostomy may also require to be $25 \mathrm{~mm} . \mathrm{Hg}$. The result will be that during both inspiration and expiration the intrathoracic pressure may be as much as $25 \mathrm{~mm} . \mathrm{Hg}$ almost continuously. Applying suction during the pump's expiratory phase will only accelerate air trapping in the emphysematous patient.

The persistent rise in intrathoracic pressure will seriously impede venous return of blood to the heart. This is shown in Fig. 7. The intraœsophageal pressure, which is identical with the intrathoracic pressure, is shown in the lower half of the tracing. When the intrathoracic pressure is raised some $40 \mathrm{~mm} . \mathrm{Hg}$ the effective right atrial pressure $(\mathrm{dRa}=$ right atrial pressure minus œsophageal pressure, measured by a differential manometer) falls towards zero as venous return to the heart is prevented by the sustained increase in intrathoracic pressure. When the intrathoracic pressure is allowed to return to normal, the right atrial pressure rises once more as venous return to the heart is resumed. Notice also that inspiration, being accompanied by a fall in intrathoracic pressure, assists venous return to the heart with a consequent rise in effective right atrial pressure during inspiration.

Fig. 8 shows a similar record with œsophageal pressure below and effective pulmonary artery pressure above. When the intrathoracic pressure is raised suddenly for a short period, right heart output is so impaired that pulmonary arterial pressure falls to very low levels indeed.

Fig. 9 shows a typical record from a patient with poliomyelitis undergoing positive pressure ventilation in whom the inspiratory pressure was increased from $5 \mathrm{~cm} . \mathrm{H}_{2} \mathrm{O}$ (left-hand record) to I $5 \mathrm{~cm} . \mathrm{H}_{2} \mathrm{O}$ (right-hand record).

The effective central venous pressure, or right heart filling pressure, may be calculated by subtracting the osophageal pressure (OES) from the central venous pressure (CVP) for each phase of the pump cycle shown in the records. The blood pressure (BP) measured by a needle in the 


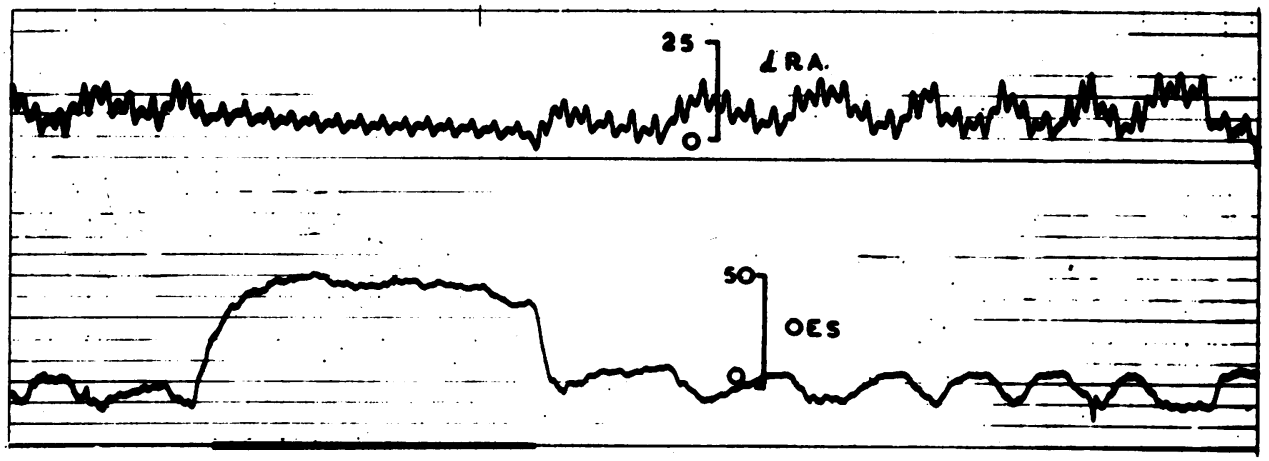

Fig. 7.- The effects of variations in intra-thoracic pressure upon the effective right atrial pressure (d RA). $\vec{\omega}$ OES = Intra-thoracic pressure, measured via an osophageal catheter.

d RA = Right atrial minus csophageal pressure, measured with a differential manometer system, calibrated in mm.Hg.

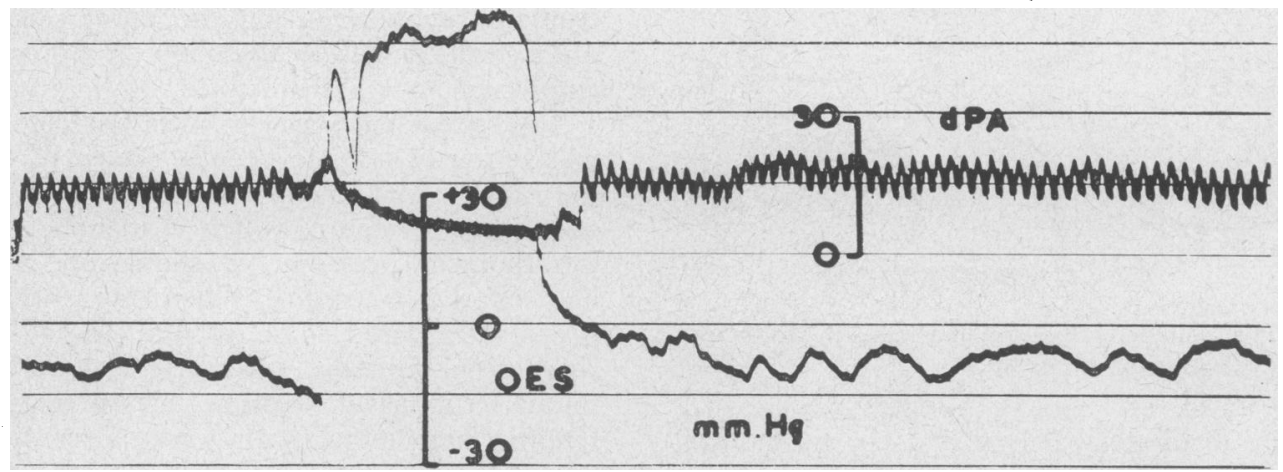

FIG. 8. - The effects of variations in intra-thoracic pressure (OES) upon the effective pulmonary arterial pressure (d PA)

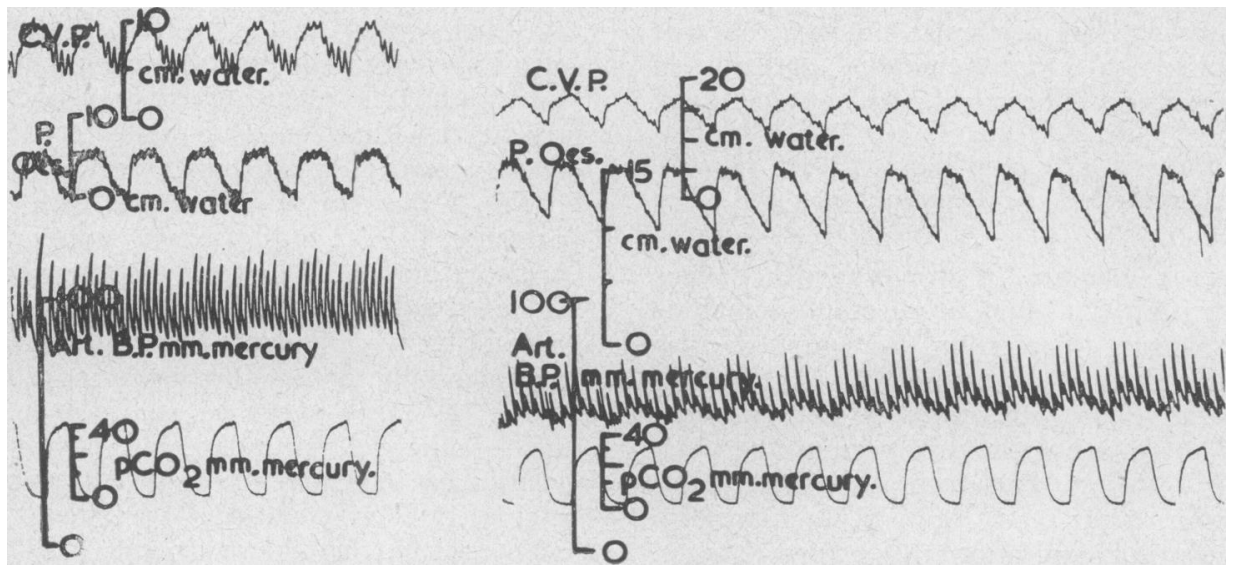

Fig. 9. - The effects of increasing the pressure of the positive phase of intermittent positive pressure respiration.

Left-hand record: Positive pressure phase limited to $5 \mathrm{~cm} . \mathrm{H}_{2} \mathrm{O}$.

Right-hand record: Positive pressure phase raised to $15 \mathrm{~cm} . \mathrm{H}_{2} \mathrm{O}$.

CVP = Central venous pressure.

P Oes = OEsophageal pressure.

Art BP $=$ Brachial arterial pressure.

$\mathrm{PCO}_{2}=$ Expired air carbon dioxide tension. 
brachial artery is shown beneath these two records.

During positive pressure ventilation inducing a $5 \mathrm{~cm}$. $\mathrm{H}_{2} \mathrm{O}$ pressure rise in the thorax (left-hand record) there was an effective venous filling pressure of approximately $5 \mathrm{~cm}$. of $\mathrm{H}_{2} \mathrm{O}$. During the expiratory phase of respiration the effective venous filling pressure was still approximately $5 \mathrm{~cm} . \mathrm{H}_{2} \mathrm{O}$ so that there was little alteration in right heart filling or cardiac output, manifest by very little change in brachial artery pulse pressure.

. However, the right-hand record shows the serious change that took place when the positive pressure phase of ventilation was increased to ${ }_{15} \mathrm{~cm}$. $\mathrm{H}_{2} \mathrm{O}$. During this phase of ventilation the effective venous filling pressure was reduced to approximately $2 \mathrm{~cm}$. $\mathrm{H}_{2} \mathrm{O}$ and it rose during expiration to approximately $4 \mathrm{~cm} . \mathrm{H}_{2} \mathrm{O}$. This seriously reduced cardiac output, and the mean arterial blood pressure fell. There was also a considerable decrease in stroke output during the positive phase of ventilation, indicated by the episodic reduction in brachial artery pulse pressure with each ventilatory cycle.

In patients with severe air trapping from emphysema the persistent rise in intrathoracic pressure that may occur as a result of intermittent positive pressure ventilation may produce a catastrophic fall in cardiac output. This may lead to sudden death within minutes of commencing positive pressure ventilation in patients with cor pulmonale unless early warning is obtained from continuous blood pressure records. These circulatory hazards may be partly avoided by using a very slow pump frequency to allow a long expiratory period.

In our experience the effects of air trapping have been a serious hazard in the use of positive pressure ventilation in patients with both cor pulmonale and acute respiratory failure.

\section{Summary}

I. The causes of acute cor pulmonale are discussed. Its frequency of occurrence over a threeyear period in the United Oxford Hospitals is reported.

2. The treatment of acute cor pulmonale is briefly réviewed, and some circulatory effects of intermittent positive pressure ventilation are described.

\section{Acknowledgments}

My thanks are due to Dr. R. M. Marshall.for permission to reproduce Figs. 5 and 6 , and to Dr. W. Watson for Fig. 9 .

I wish to thank Dr. S. M. S. Mody for his help in analysing the hospital records quoted in this paper.

\section{REFERENCES}

Anderson, D. P., Allen, W. J., Barcroft, H., Edholm, O. G., and Manning, G. W. (1946): Circulatory Changes During Fainting and Coma Caused by Oxygen Lack, Y. Physiol. (Lond.), 104, 426.

Assmussen, E., and Nielsen, M. (1955): Cardiac Output in Rest and Work at Low and High Oxygen Pressures, Acta physiol. scand., 35, 73.

Berger, E. Y., Galdston, M., and Horwitz, S. (1949): The Effect of Anoxic Anoxia on the Human Kidney, $\mathcal{F}$. clin. Invest., 28,648 .

Camprell, E. J. M., and Short, D. S. (1960): The Cause of Oedema in 'Cor Pulmonale', Lancet, i, Ir84.

- (1960): Respiratory Failure: The Relation Between Oxygen Concentrations of the Inspired Air and Arterial Blood, Ibid., ii, ro.

(1960): A Method of Controlled Oxygen Administration which Reduces the Risk of Carbon-dioxide Retention, Ibid., ii, 12.

Ciba Foundation Guest Symposium Report (1959): Terminology, Definitions, and Classification of Chronic Pulmonary Emphysema and Related Conditions, Thorax, 14, 286.

Defares, J. G., Lundin, G., Aborelius, M., Jr., Stromblad, R., and Svanberg, L. (1959): Effect of Unilateral Hypoxia on Pulmonary Blood Flow Distribution in Normal Subjects, F. appl. Physiol., 15, 169.

Doyle, J. T., Wilson, J. S., and Warren, J. V. (1952): Pulmonary Vascular Responses to Short-term Hypoxia in Human Subjects, Circulation, 5, 263.

Ferrer, M. I., Harvey, R. M., Cathcart, R. T., Webster, C. A., Richards, D. W., and Cournand, A. (ig5o): Some Effects of Digoxin Upon the Heart and Circulation in Man: Digoxin in Cor Pulmonale, Circulation, $\mathbf{I}$, I6r.

Fishman, A. P., Maxwell, M. H., Crowder, C. H., and Morales, P. (1951): Kidney Function in Cor Pulmonale, Ibid., 3,703 .

Herz, C. W. (1956): Untersuchungen uber den Einfluss der Alveolaren Gasdruche auf die Intrapulmonale Durchblutungsvertechung biem Menschen, Klin. Wschr., 34, 472.

Hickam, J. B., and Cargill, W. H. (I948): Effects of Exercise on Cardiac Output and Pulmonary Artery Pressure in Normal Persons and in Patients with Cardiovascular Disease and Pulmonary Emphysema, $\mathcal{F}$. clin. Invest., 27, 10.

HowarTh, S., McMichael, J., and SharPeY-Schafer, E. P. (1948): Effects of Oxygen, Venesection, and Digitalis in Chronic Heart Failure from Disease of the Lungs, Clin. Sci., 6, 187.

KetY, S. S., and Schmidt, C. F. (1948): The Effects of Altered Arterial Tensions of Carbon Dioxide and Oxygen on Cerebral Blood Flow and Cerebral Oxygen Consumption of Normal Man, F. clin. Invest., 27, 484.

KorNer, P. I. (1959): Circulatory Adaptations in Hypoxia, Physiol. Rev., 39, 687.

MANFredi, F., and Sieker, H. O. (1960): The Effect of Carbon Dioxide on the Pulmonary Circulation, F. clin. Invest., 39, 295. 
McArdie, L., Roddie, I. C., Sheppard, J. T., and Whelan, R. F. (1957): The Effect of Inhalation of $30 \%$ Carbon Dioxide on the Peripheral Circulation of the Human Subject, Brit. F. Pharmacol., 12, 293.

McMichael, J., and SHARPEY-Schafer, E. P. (1944): The Action of Intravenous Digoxin in Man, Quart. F. Med., $\frac{3}{\mathrm{D}}$ $13,123$.

Rich, M., Scheingerg, P., and Belle, M. S. (1953): The Relationship Between Cerebrospinal Fluid Pressure Changes. $\subseteq$ and Cerebral Blood Flow, Circulat. Res., r, 389.

SARNOFF, S. J., and BERgLund, E. (1954): Ventricular Function: I.-Starling's Law of the Heart Studied by Means of $\stackrel{\overrightarrow{\vec{A}}}{\rightarrow}$ Simultaneous Right and Left Ventricular Function Curves in the Dog, Circulation, 9, 706.

Watson, W. (1960): Personal communication.

WestLAKE, E. K., Simpson, T., and KAYE, M. (1955): Carbon Dioxide Narcosis in Emphysema, Quart. F. Med., 2, 155. and CAMPBELl, E. J. M. (1959): Effects of Aminophylline, Nikethamide, and Sodium Salicylate in Respiratory Failure, Brit. med. $\mathcal{F}$., i, 274.

Wolff, H. P., KoczoreK, Kh. R., and Buchborn, E. (1957): Hyperaldosteronism in Heart Disease, Lancet, ii, 63. 